\title{
AVALIAÇÃO NA EDUCAÇÃO A DISTÂNCIA: categorias de análise da atividade de tutoria
}

\author{
Fabiana Pinto de Almeida BIZARRIA ${ }^{1}$ \\ Maria Aparecida da SILVA ${ }^{2}$ \\ Carlos André Moura BARROS ${ }^{3}$ \\ Maria do Socorro Maia SILVA ${ }^{4}$ \\ Alexandre Oliveira LIMA ${ }^{5}$
}

\begin{abstract}
${ }^{1}$ Doutoranda em Administração. Psicóloga Organizacional na Universidade da Integração Internacional da Lusofonia Afro-brasileira.bianapsq@hotmail.com

${ }^{2}$ Doutora em Engenharia de Produção. Professora na Universidade da Integração Internacional da Lusofonia Afrobrasileira.mapasilva@unilab.edu.br
\end{abstract}

${ }^{3}$ Especialista em Gestão de Pessoas. Administrador na Universidade da Integração Internacional da Lusofonia Afrobrasileira. carlosandre@unilab.edu.br

${ }^{4}$ Mestranda em Políticas Públicas e Gestão da Educação Superior. Pedagoga na Universidade da Integração Internacional da Lusofonia Afro-brasileira.smaia@unilab.edu.br

${ }^{5}$ Doutor em Administração. Professor na Universidade da Integração Internacional da Lusofonia Afro-brasileira. alexandrelima@unilab.edu.br

Recebido em: 17/06/2016 - Aprovado em: 21/10/2016 - Disponibilizado em: 18/12/2016

\begin{abstract}
RESUMO:
Na perspectiva de contribuir com a discussão sobre avaliação na Educação a Distância (EaD), a pesquisa empreendeu estudo sobre aspectos da atividade de tutoria com vistas a elaborar categorias para avaliação desses atores. Para tanto, realizou-se pesquisa de campo em uma instituição de Ensino Superior pública federal, com tutores (45 a distância e 28 presenciais) e 145 discentes, vinculados a 4 cursos(bacharelado em Administração Pública e as especializações - Gestão Pública, Gestão em Saúde e Gestão Pública Municipal) oferecidos em 6 polos de apoio presencial (5 no Ceará e 1 na Bahia). Os dados foram coletados por meio de questionário com questões abertas, analisados com suporte na análise de conteúdo, com auxílio do software Atlas ti, com base em três eixos: caracterização do sistema EaD (eixo 1), mediação pedagógica da tutoria a distância (eixo 2) e o elo discente-instituição da tutoria presencial (eixo 3), os dois últimos analisados sob o ponto de vista dos tutores e dos discentes.Infere-se que os tutores manifestam-se em torno de um perfil ideal, ressaltando as qualidades para o exercício da tutoria e os discentes indicam aspectos reais cotidianos que impactam o processo de ensino-aprendizagem. Considera-se pertinente pensar em processos avaliativos que agreguem os diferentes pontos de vistas, sendo o retorno periódico dessas avaliações um exercício necessário à credibilidade da própria avaliação e, também, favorável a construção do diálogo e melhoria da qualidade dos processos.
\end{abstract}

Palavra-chave: Tutoria. Avaliação. Educação a Distância. Categoria. Educação Superior.

\section{ABSTRACT:}

In order to contribute to the discussion on evaluation in Distance Education (EAD), the research undertaken study on aspects of mentoring activity in order to prepare categories for evaluation of these actors. Therefore, we carried out field research in an institution of federal higher education with tutors (45 distance and 28-person) and 145 students, linked to 4 courses (BA in Public Administration and specialization - Public Administration, Management in health and Municipal Public Management) offered in 6-face support poles (5 in Ceará and one in Bahia). Data were collected through a questionnaire with open questions, analyzed with support in content analysis, with the help of Atlas ti software, based on three axes: characterization of the distance education system (axis 1), pedagogical mediation mentoring distance (axis 2) and the student-institution link in the classroom tutoring (axis 3), the last two analyzed from the point of view of the tutors and students. It is inferred that the tutors are manifested around an ideal profile, emphasizing the qualities for the exercise of tutoring and students indicate real everyday issues that impact the teaching-

927

Revista da Universidade Vale do Rio Verde, Três Corações, v. 14, n. 2, p. 927-945, ago./dez. 2016 
learning process. It considered appropriate to think of evaluation processes that add the different points of views, and the periodic return of these assessments a necessary exercise to the credibility of the evaluation and also in favor of constructive dialogue and improving the quality of processes.

Keywords: Tutoring. Evaluation. Distance Education. Category. College education.

\section{Introdução}

Inserida em um contexto dinâmico e instigada pelas mudanças nas políticas educacionais, contínua evolução tecnológica e contingências de ordem política e econômica, a Educação à Distância $(\mathrm{EaD})$ vem se consolidando como uma política de sucesso que impacta no desenvolvimento educacional do país, tornando-se assim, uma ferramenta de diversificação e expansão do sistema educacional (BRUNETTA et al., 2013; ALMEIDA; MARROIG; PINTO， 2014; MEDEIROS; MOSER; SANTOS, 2015).

A EaD tem se consolidado no cenário educacional, diante da perspectiva de democratização no ensino, ampliando as possibilidades de formação acadêmica e profissional (FREITAS; FRANCO, 2014; LANZA; KUABARA, 2015). A despeito dessas dinâmicas e práticas formativas na modalidade EaD, a institucionalização de cursos nessa modalidade, em nível superior, são recentes (BRASIL, 2016).

Os dados do Censo da Educação Superior evidenciam que essa modalidade de ensino tem se desenvolvido de modo significativo nos últimos anos, apresentando um expressivo crescimento no número de cursos de graduação ofertados $(35,3 \%)$, com o aumento de 930 cursos em 2010 para 1258 em 2013. No mesmo período de referência, as matriculas dessa modalidade evoluíram de 930.179 para 1.153.572, representando $24 \%$ de aumento no número total de matriculados e adquirindo representatividade no ensino superior brasileiro (BRASIL, 2015)

Em decorrência desse crescimento, observa-se a necessidade e relevância de avaliação constante da qualidade e eficácia das ações que a $\mathrm{EaD}$ vem desenvolvendo e como tem desempenhando seu papel na formação de ensino superior. Neste aspecto, estudos realizados por Abbad, Zerbini, e Souza (2010), Martins e Zerbini (2014) indicam que existe uma carência de pesquisas nesta área, especialmente no tocante à qualidade, eficácia e processo de ensino aprendizagem em $\mathrm{EaD}$.

A atuação de tutores presenciais e a distância tem sido objeto de estudos e pesquisas diversas, principalmente no que diz respeito ao papel do tutor como mediador de aprendizagem e às competências e habilidades que devem constituir o perfil desses profissionais (ZERBINI; ABBAD, 2009; 


\section{SARQUIS; CAVALCANTE, 2014;} MENDES 2012; BIZARRIA et al., 2015), contudo, acredita-se que pesquisas que colaborem com dimensões para avaliação de tutores podem auxiliar o diagnóstico laboral desses sujeitos com base no desempenho e na atuação em $\mathrm{EaD}$, considerando a distinta relação entre tutor-aprendiz com ênfase na interação por meio de recursos tecnológicos (BELLONI, 1999).

Dessa forma, percebe-se a necessidade de pensar em categorias de avaliação do tutor no sistema $\mathrm{EaD}$, sendo tema ainda pouco explorado (RONCHI; ENSSLINL; ENSSLIN, 2012; MARTINS; ZERBINI, 2014), haja vista que esse ator emerge como o profissional com importante impacto para a garantia de permanência do aluno, considerando a "capacidade de acolher as demandas específicas em virtude da sua condição de estar na ponta do sistema, em interação permanente com o aluno". (BIZARRIA et al., 2015, p. 101).Além disso, “em função do aumento da oferta de cursos à distância, também passa a ser uma necessidade crescente melhorar as estratégias de Planejamento e de Gestão dos cursos de EAD.” (RISSI et al., 2012, p. 1).

Diante desse contexto, a pesquisa objetiva levantar categorias de análise da atividade de tutorias, com vistas a cooperar com o processo de avaliação desses atores. De forma específica, dois caminhos são considerados com base na leitura de Demo (2012) e Bizarria et al. (2015): (i) descrever a realidade da investigação por meio da caracterização do sistema $\mathrm{EaD}$ na instituição investigada e (ii) qualificá-la, tendo por base critérios previamente estabelecidos, especificamente a mediação pedagógica da tutoria a distância e o elo discente-instituição da tutoria presencial.

\section{Avaliação da atividade de tutoria na EaD}

Há consenso em relação ao papel fundamental do processo de tutoria para o bom desempenho do discente no âmbito da EaD (BELONI, 2003; WROBEL et al., 2010; MEDEIROS; MOSER; SANTOS, 2015), à medida que a tutoria exerce suporte à construção do conhecimento, por meio da interatividade, facilitando a condução dos obstáculos inerentes ao processo de aprendizagem.

Considera-se, ainda, que as tecnologias agregadas ao ensino e a aprendizagem, referenciadas em teorias sócio construtivistas, incorporam novas práticas à construção do conhecimento na $\mathrm{EaD}$ (HONANDA; PINHEIRO; PAGLIUCA, 2013), o que impõe diversificação do fazer pedagógico, na fronteira da mediação do saber, atrelado à novas habilidades, conhecimentos e atitudes aos processos de trabalho, em função “(...) de um processo de 
produção de conhecimento em fluxo". (TARCIA; CABRAL, 2012, p. 148)

Ao mesmo tempo, sendo prática social-educativa-dialógica de trabalho coletivo, a EaD precisa assumir o conhecimento em fluxo na arquitetura pedagógica e ser elemento de gestão, na perspectiva de colaborar com a formação que extrapole a condição de autonomia, sendo esta inerente ao perfil virtual, mas consiga imprimir qualidade e criticidade a um corpo discente ávido por conhecimento em detrimento da informação (FREIRE, 2006;BRASIL， 2016).Assim, a atividade pedagógica da tutoria, associa-se à prática crítica, implicante do pensar certo, e envolve o movimento dinâmico, dialético, entre o fazer e o pensar sobre o fazer (FREIRE, 2006).

No que tange à mediação didáticopedagógica do ensino e aprendizagem em EaD, (BRASIL, 2016). Ao tutor, são atribuídas as funções educativa-pedagógica e social de construção de vínculos, à medida que reúne um conjunto ideal de atividades com representação nessas duas funções, seja por precisar ter domínio do conhecimento (MENEGUETTI, 2004), para orientar o aluno na execução das atividades (BELLONI, 2003), seja incentivando o discente a questionar e contrapor o conhecimento e suas práticas sociais (PRETI, 2003), por meio da interação contínua e provocativa, capaz de gerar motivação (HOLMBERG, 1996). Além dessas, há necessidade de "competências pessoais tais como paciência, tolerância, habilidade em operar computadores, entre outros". (RONCHI;ENSSLIN; ENSSLIN, 2012, p. 60).

A realização da mediação se dá nos espaços interativos, onde são veiculados os conteúdos dos cursos, a comunicação entre os principais atores da $\mathrm{EaD}$ e por onde a necessidade de competências relacionais, interacionais e referentes às tecnologias ficam evidenciadas. Ressalta-se que os ambientes virtuais de aprendizagem permitem maior participação desses atores, o que enriquece o processo pedagógico (FRANKLIN; VAN HARMELEN, 2007), porém a autonomia circunscrita, em geral, ao discente, também permeia a realidade desses profissionais, associado à diferentes expectativas em relação à competências e atribuições (BIZARRIA, 2014). Nesse sentido, torna-se essencial vislumbrar a $\mathrm{EaD}$ como um processo educativo sistemático e organizado, com clara definição de seus processos e tomadas de decisão, com base na proposta educativa e nos interesses dos grupos (LANZA; KUABARA, 2015).

Pelo teor funcional do trabalho do tutor, em associação à discussão sobre qualidade do ensino da EaD, a gestão da tutoria evoca a necessidade de incorporar processos avaliativos que visem o 
desenvolvimento do sistema, com ganhos em termos de melhoria da gestão e do desempenho dos discentes (ZERBINI; ABBAD, 2009; RONCHI; ENSSLIN; ENSSLIN, 2012), e ainda que considere as funções de planejamento, implementação e gestão dos cursos a distância, integradas às três categorias profissionais: docentes, tutores e pessoal técnico-administrativo (VALENTE; MORAN, 2011).É uma equipe multidisciplinar, com diferentes competências (formadores, conteudistas, revisores, pesquisadores), Coordenadores (de polo, de tutoria, de curso, de programas, da UAB), profissionais diversos que atuam com os sistemas da informação e os tutores (presenciais e a distância) (BIZARRIA et al., 2015), designer instrucionais, designers gráficos, monitores, revisores e tutores (RISSI et al., 2012).

Ao mesmo tempo, as instituições precisam planejar e implementar sistemas de avaliação institucional que privilegie um processo permanente e consequente, de forma a "subsidiar o aperfeiçoamento dos sistemas de gestão e pedagógico, realizando efetivamente correções na direção da melhoria da qualidade do processo". (VALENTE; MORAN, 2011, p. 61).Estes Sistemas funcionam em rede e, por isso, apresentam necessidade de participação, descentralização e integração entre atores e funções (BERNARDI;

DAUDT;

BEHAR2013), além de satisfazer requisitos de aprendizagem coerentes com a sociedade do conhecimento (SUN et al., 2008), e capazes de integrar inovação aos seus processos (SOUZA; FARIA, 2013; ARAÚJO et al., 2013)

Nesse sentido, de forma anterior à discussão da relação avaliação-desempenho, com base em estudos correlatos, apresenta-se algumas concepções e conceitos considerados relevantes em $\mathrm{EaD}$ e pertinentes à esta pesquisa $\mathrm{O}$ quadro 1 indica que há diferentes modelos de sistemas $\mathrm{EaD}$ e que, cada um deles ou suas variações, expressa uma forma de atuação dos seus atores, que resulta em possibilidades diferenciadas de composição dos recursos humanos necessários à estruturação e ao funcionamento de cursos nessa modalidade (VALENTE; MORAN, 2011).

Quadro1 - Principais modelos de sistemas de Educação a Distância

\begin{tabular}{|l|l|}
\hline \multicolumn{1}{|c|}{ Modelos } & \multicolumn{1}{c|}{ Característica } \\
\hline Modelo & $\begin{array}{l}\text { Com suporte em teleaula e/ou } \\
\text { vídeo aula, com aulas transmitidas } \\
\text { por satélite (ao vivo) ou aulas } \\
\text { produzidas em estúdio, com } \\
\text { mediação de tutores presenciais e a } \\
\text { distância para aprofundamento de } \\
\text { questões relacionadas com a aula } \\
\text { dada. }\end{array}$ \\
\hline $\begin{array}{l}\text { Modelo } \\
\text { (virtual }\end{array}$ & $\begin{array}{l}\text { Com suporte em materiais } \\
\text { impressos e digitais, com tutorias } \\
\text { presencial) }\end{array}$ \\
& $\begin{array}{l}\text { presencial em polos e/ou virtuais, } \\
\text { pela internet. Esse modelo utiliza } \\
\text { vídeo aulas acessadas via web. Os } \\
\text { alunos realizam suas atividades em } \\
\text { casa e as entregam a um tutor on- } \\
\text { line num Ambiente de } \\
\text { Aprendizagem Virtual on-line, } \\
\text { como o Moodle. Os alunos só vão } \\
\text { ao polo para avaliação on-line. }\end{array}$ \\
\hline Fonte: Adaptado de Valente e Moran (2011)
\end{tabular}


O modelo web semipresencial é o adotado pelas universidades pública, sob a gestão da Universidade Aberta e a Distância, criado em 2006, pelo Decreto $n^{\circ} 5.800$, por meios de seus programas e sistemas de regulação e avaliação, com fortes parcerias entre as esferas federais, estaduais e municipais do governo. Tanto as instituições públicas, como as instituições privadas são reguladas pela $U A B$.

A tutoria no modelo web semipresencial possui dois aspectos da tutoria a serem considerados: o espaço e o tempo, à medida que se organizam na figura dos tutores a distância e presencial(BRASIL, 2016), que, ao mesmo tempo que possuem a atribuição de reduzir distâncias transacionais, privilegiam o diálogo nessa condução (MOORE; KEARSLEY, 2008), haja vista que a educação é, por princípio, dialógica (FREIRE, 1983).

Em pesquisa sobre percepção sobre o papel do tutor por parte de profissionais de $\mathrm{EaD}$, Bizarria et al. (2015) identificou duas questões que precisam ser melhor exploradas, $\mathrm{o}$ aspecto do vínculo estabelecido pelo tutor e a consequência motivacional dessa ligação afetiva e, também, a necessidade de melhor investigar o perfil do tutor, com amparo nessa expectativa de construção de elos. Ao mesmo tempo, essa interação entre tutores e discentes podem repercutir na problemática da evasão, constituindo em maior identificação com os cursos e com a instituição, o que pode favorecer a uma melhor resposta às múltiplas dificuldades geradoras de resistências e desistências.

Quadro 2 - Resumo da percepção sobre tutor por parte dos Profissionais de EaD

\begin{tabular}{|c|c|c|}
\hline Estratégias & $\begin{array}{c}\text { Principais } \\
\text { propriedades }\end{array}$ & $\begin{array}{l}\text { Principais } \\
\text { dimensões }\end{array}$ \\
\hline Tutor & $\begin{array}{l}\text { Responsável } \\
\text { pelo } \\
\text { acompanhame } \\
\text { nto e contato } \\
\text { com o aluno. } \\
\text { Perfil do tutor. }\end{array}$ & $\begin{array}{lr}\text { Principal } & \text { ator } \\
\text { envolvido } & \text { do } \\
\text { processo } & \text { de } \\
\text { vinculação } & \mathbf{a o} \\
\text { curso } & \mathbf{a} \\
\text { instituição. } & \\
\text { Necessidade } & \text { de } \\
\text { repensar o perfil do } \\
\text { tutor. }\end{array}$ \\
\hline
\end{tabular}

Fonte: Bizarria et al. (2015, p. 100)

Portanto, a estratégia de contato e de constituição de vínculos favorece o acolhimento, a autoconfiança e a motivação do aluno, e, assim, repercute de forma positiva no sucesso escolar dos estudantes. Para tanto, aspectos avaliativos que privilegiem a mediação pedagógica precisa, também, considerar a vinculação discenteinstituição por meio dos processos de tutoria, sendo ela pedra fundamental da vinculação do aluno à instituição e ao curso, com enfoque numa abordagem diferenciada, denominada como abordagem interpessoal.

Além de explorar os modelos em EaD e situar a tutoria no modelo web semipresencial, o quadro 3 informa as principais atribuições dos tutores de acordo com as normativas preconizadas pela Universidade Aberta e a Distância. 
Quadro 3-Definição e principais atribuição de tutores, presencial e a distância

\begin{tabular}{|c|c|}
\hline Categoria & Descrição das principais atribuições \\
\hline $\begin{array}{l}\text { Tutoria a } \\
\text { Distância }\end{array}$ & $\begin{array}{l}\text { Atua a partir da instituição, mediando o } \\
\text { processo pedagógico junto a estudantes } \\
\text { geograficamente distantes, } \\
\text { referenciados aos polos descentralizados } \\
\text { de apoio presencial. Sua principal } \\
\text { atribuição deste profissional é o } \\
\text { esclarecimento de dúvidas através } \\
\text { fóruns de discussão pela Internet, pelo } \\
\text { telefone, participação em } \\
\text { videoconferências, entre outros, de } \\
\text { acordo com o projeto pedagógico. } \\
\text { Responsabilidade de promover espaços } \\
\text { de construção coletiva de conhecimento, } \\
\text { selecionar material de apoio e } \\
\text { sustentação teórica aos conteúdos e, } \\
\text { frequentemente, faz parte de suas } \\
\text { atribuições participar dos processos } \\
\text { avaliativos de ensino-aprendizagem, } \\
\text { junto com os docentes. }\end{array}$ \\
\hline $\begin{array}{l}\text { Tutoria } \\
\text { Presencial }\end{array}$ & $\begin{array}{l}\text { Atende os estudantes nos polos, em } \\
\text { horários pré-estabelecidos. Este } \\
\text { profissional deve conhecer o projeto } \\
\text { pedagógico do curso, o material didático } \\
\text { e o conteúdo específico dos conteúdos } \\
\text { sob sua responsabilidade, a fim de } \\
\text { auxiliar os estudantes no } \\
\text { desenvolvimento de suas atividades } \\
\text { individuais em grupo, fomentando o } \\
\text { hábito da pesquisa, esclarecendo } \\
\text { dúvidas em relação a conteúdos } \\
\text { específicos, bem como ao uso das } \\
\text { tecnologias disponíveis. Participa de } \\
\text { momentos presenciais obrigatórios, tais } \\
\text { como avaliações, aulas práticas em } \\
\text { laboratórios e estágios supervisionados, } \\
\text { quando se aplicam.O tutor presencial } \\
\text { deve manter-se em permanente } \\
\text { comunicação tanto com os estudantes } \\
\text { quanto com a equipe pedagógica do } \\
\text { curso. }\end{array}$ \\
\hline
\end{tabular}

Fonte: Adaptado de Brasil (2007, 2016)

Constata-se, pelo quadro 3 , que há sobreposição de funções atribuídas à tutores a distância e presencial. Porém, destaca-se a posição da mediação pedagógica no âmbito da atuação virtual e a função de elo na atuação presencial, exercidas nos polos de apoio presencial vinculados as Universidades.

Há, também, modelos de tutoria, em geral, composto pelos modelos tutorgeneralista (que acompanha todas as disciplinas), e tutor por área ou de tutorespecialista em áreas específicas(VALENTE; MORAN, 2011). A adoção de diferentes modelos também colabora para possibilidades diferenciadas de avaliação, a medida que o desenho desse padrão também condicionará processos seletivos, como forma de incorporar ao sistema profissional as competências definidas em cada modelo.

Portanto, um sistema de avaliação da atividade de tutoria assume prerrogativas que extrapolam a condição metodológica instrumental, para abrigar o sistema como modalidade educativa que se organiza por meio do tripé metodologia , gestão e avaliação, que, por sua vez, devem se materializar na ação articulada entre as políticas, o PDI, as Diretrizes Curriculares e o PPC (BRASIL, 2016) e, nesse caminho, acredita-se em um sistema de avaliação aberto, capaz de considerar características institucionais, o modelo de sistema $\mathrm{EaD}$ e de tutoria adotados, com suporte na função de mediação pedagógica e construção de vínculos, sendo estas, inclusive, consideradas representações sociais da tutoria em $\mathrm{EaD}$ (BRUNETTA et al., 2013).

Igualmente, acredita-se em sistemas avaliativos configurados pela apreensão dos significados atribuídos à tutoria por meio de seus principais componente (discente, 
docente, tutores, e, também, autoavaliações), a medida que avaliação atua no sentido de conhecer, compreender, orientar e reorientar processos e ações (BELLONI; MAGALHÃES; SOUSA, 2007). Nesse sentido, a percepção discente sobre o tutor contempla uma avaliação objetiva, das expectativas e do desempenho desses sujeitos (HATTIM-JANSSEN; VANCONCELOS, 2008) e a avaliação entre tutores a distância e presencial, permite compreensão de como se processa a distinção da leitura da atividade de tutoria pelo olhar dessa distinção.

O trabalho de tutoria depara-se com instrumentos cada vez mais sofisticados, o que exige novas habilidades e avaliação das práticas para que possa construir referências de atuação (MAGGIO, 2001). Alguns instrumentos de avaliação indicam a necessidade de discernir funções operacionais das funções pedagógicas (RONCHI; ENSSLIN; ENSSLIN, 2012), procedimentos e meios instrucionais adotados(ZERBINI; BORGES-FERREIRA; ABBAD, 2012), e de apoio ao próprio sistema, pelo feedback oportunizado pelas reuniões de acompanhamento dos cursos (PASSOS; BATTESTIN, 2016).

Sem a pretensão de elaborar um instrumento único, geral, e fechado, acreditase que há necessidade de aprofundamento sobre dois eixos: (i)mediação pedagógica e (ii)elo discente-instituição, sendo eles coordenados por uma estrutura de curso, pelo diálogo e pela autonomia discente (MOORE; KEASLEY, 2008). Nessa perspectiva, esta pesquisa considera a ação avaliativa, como uma maneira de verificar a qualidade de dada realidade, não sendo uma instância que resolve problemas ou que inova, mas uma forma de investigar a qualidade de alguma coisa, produto, pessoa ou situação, propiciando a base para atos regulatórios e de acompanhamento, sendo, também, um juízo de qualidade sobre dados relevantes, tendo em vista uma tomada de decisão (LUCKESI, 2011; DEMO; 2012).

Acrescenta-se, ainda, que a avaliação permite uma reflexão sobre possíveis ajustes e feedback, considerando a efetividade dos resultados. Além disso, contribui para revisar estratégias implementadas de forma a melhor definir critérios, ferramentas e condução dos cursos (MAYFIELD, 2011).

Nessa ótica, a avaliação pode ser tomada como ferramenta de julgamento da atividade tutorial e artifício propiciador para processos decisórios relacionados ao desenvolvimento institucional, fortalecimento da qualidade do ensino, com suporte no estímulo ao desenvolvimento de sistemas tutoriais em $\mathrm{EaD}$, inclusive, como forma de refletir sobre a atividade desenvolvida e o contexto que favorece esse desenvolvimento.

Nesta expectativa, torna-se relevante considerar as diferentes concepções e 
perspectivas da avaliação e atentar para suas possíveis implicações políticas, econômicas, culturais e epistemológicas. É importante ressaltar, ainda, que o desenvolvimento de uma ação avaliativa sempre estará pautado em contextos e objetivos específicos.

\section{Metodologia de pesquisa}

Realizou-se pesquisa exploratória fundamentada na metodologia qualitativa, buscando evidenciar dimensões relacionadas à de avaliação de tutores, com vistas à discutir o desempenho dos tutores presenciais e à distância dos cursos oferecidos pela Diretoria de Educação Aberta e à Distância da Universidade da Integração Internacional da Lusofonia Afro-Brasileira - UNILAB.

A abordagem escolhida, qualitativa, privilegia maior abertura as falas dos sujeitos pesquisados, sendo o sujeito pesquisador observador do contexto sociais de implicação dessas falas, do lugar de onde elas são produzidas (DENZIN; LINCOLN, 2006), considerando, ainda, a abordagem compreensiva de relações e percepções de um determinado fenômeno, objetivando produzir conhecimento sobre o objeto de investigação (MINAYO, 2007) Assim, por meio leitura qualitativa buscam-se os significados e às problemáticas dos atores da $\mathrm{EaD}$ em suas práticas cotidianas (FLICK, 2009; MERRIAN, 1998), especificamente tutores e discentes, numa perspectiva de avaliações (tutores e discentes) e autoavaliações (tutores). Para tanto, três perfis de respostas são considerados para a análise: a avaliação entre tutores, a autoavaliação e a avaliação discente.

Os dados foram coletados por meio de questionário aberto, contendo perguntas sobre a atuação do tutor para tutores e discentes, sugestões para como a tutoria atuaria para aprimorar as disciplinas e o curso para discentes, sugestões para o processo de avaliação da tutoria para discentes, contemplando os cursos de graduação (Bacharelado em Administração Pública) e de especialização (Gestão Pública, Gestão em Saúde e Gestão Pública Municipal).Também se considerou informações documentais para caracterizar o sistema $\mathrm{EaD}$.

No que tange à motivação da pesquisa, além de subsidiar discussões sobre avaliação de atividades de tutoria, também foi pensada pela gestão do sistema $\mathrm{EaD}$ da instituição para identificar aspectos a serem considerados pelo planejamento do setor. Assim, ressalta-se que a pesquisa empreendida se revestiu de interesses acadêmico e gerencial, à medida que se compreende que a segunda pode ser reflexo da primeira.

A pesquisa foi empreendida nos meses de 20 de abril a 30 de maio de 2015 , por meio de questionário gerado pelo Google Drive, 
cujo link foi disponibilizado no Sistema Integrado de Gestão Acadêmica (SIGAA). O SIGAA, na instituição estudada, agrega os a gestão dos cursos presencial e a distância, funcionando como Ambiente Virtual de Aprendizagem. Participaram da pesquisa 45 tutores a distância, 28 tutores presenciais e 145 discentes (70 Administração Pública, 26 Gestão em Saúde, 21 Gestão Pública, 26 Gestão Pública Municipal) distribuídos em 6 polos de apoio presencial, sendo 5 desses polos (cidades de: Aracati, Aracoiaba, Limoeiro do Norte, Piquet Carneiro, Redenção) no estado do Ceará e 1 polo (cidade de: São Francisco do Conde) no estado da Bahia.

As manifestações dos tutores e discentes foram agrupadas e importadas para tratamento no software Atlas.ti, a fim de categorizar e apreciar os enunciados por meio da análise de conteúdo (BARDIN, 2011), especificamente análise de relação, numa perspectiva de ir além da "frequência da aparição dos elementos do texto, mas para as relações que esses elementos mantêm entre si”. (BARDIN, 2011, p. 259), considerando a criatividade, imaginação e intuição dos pesquisadores, particularmente na definição dos grupos representativos e na hierarquia entre as divisões estabelecidas.

Observa-se que esta análise de conteúdo auxilia a análise dos textos transcritos no sentido de desvelar núcleos de sentido existentes nas manifestações dos sujeitos para que, em seguida, sejam agrupados em categorias mais amplas (BARDIN, 2011). Nesse caso, o software auxilia a investigação à medida que permite o cruzamento dos dados, buscando padrões e utilizando técnicas diferentes para possibilitar a observação do fenômeno através de múltiplas lentes (BANDEIRA-DE-MELLO, 2006).

Nesse sentido, para análise dos dados, inicialmente, partiu-se de categorias de análise construídas com suporte na literatura referenciada e que guiou a análise dos dados: (i) descrever a realidade da investigação por meio da caracterização do sistema $\mathrm{EaD}$ na instituição investigada (eixo 1) e (ii) qualificá-la, tendo por base critérios previamente estabelecidos, especificamente a mediação pedagógica da tutoria a distância (eixo 2) e o elo discente-instituição da tutoria presencial (eixo 3). Assim, procedeu-se investigação com base na figura 1

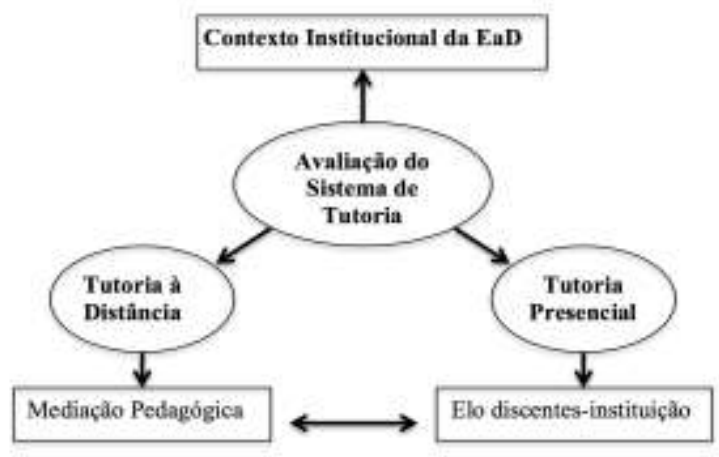

Figura 1 - Eixos de análise da pesquisa de campo Fonte: Elaborado pelos autores (2016) 
Assim, identificaram-se padrões, práticas e percepções acerca do fenômeno investigado, inspirando a formação de redes de significados atribuídos à tutoria, viabilizando a elaboração de categorias para sua avaliação.

\section{Apresentação e Análise dos dados}

Inicialmente, a codificação dos dados da pesquisa ensejaram códigos que emergiram das diversas situações descritas pelos sujeitos entrevistados. Cada um foi sugerido considerando a relevância dos enunciados para a pesquisa, os eixos de análise de acordo com Demo (2012) e Bizarria et al. (2015) e o impacto dessas categorias em um sistema de avaliação de tutores. Em seguida, o teor das entrevistas suscitaram a elaboração de outros grupos que permearam o entendimento dos eixos elencadas.

Os mapa categóricos indicam a percepção dos tutores no que diz respeito à avaliação de pares (tutor presencial<->tutor a distância) e autoavaliação (Figura 2), considerando a perspectiva dinâmica e dialética entre o fazer e o pensar sobre o fazer (FREIRE, 2006), e a percepção dos discentes no que diz respeito à avaliação de tutores (Figura 3). Essas percepções indicam como os tutores são representados por essas categorias (BRUNETTA et al., 2013), tendo como meta o aspecto avaliativo.
A organização do desenho se deu em função dos eixos de análise Mediação Pedagógica (eixo 2) e Elo discentesinstituição (eixo 3), vinculadas, respectivamente a tutoria a distância e a tutoria presencial. A ligação entre esses dois eixos ressalta que há associação entre essas funções de tutoria, sendo elas, também, pertencentes a um sistema de Educação a Distância institucional (eixo 1) simbolizado pela categoria parceria (Figura 2) e pelas categorias parceria, visita ao polo e avaliação periódica (Figura 3).

\subsection{Avaliação de Tutores: o olhar dos tutores}

A figura 2 indica a categorização, com referência nos eixos 1, 2 e 3, tendo como dados a percepção dos tutores sobre avaliação da tutoria no sistema $\mathrm{EaD}$.

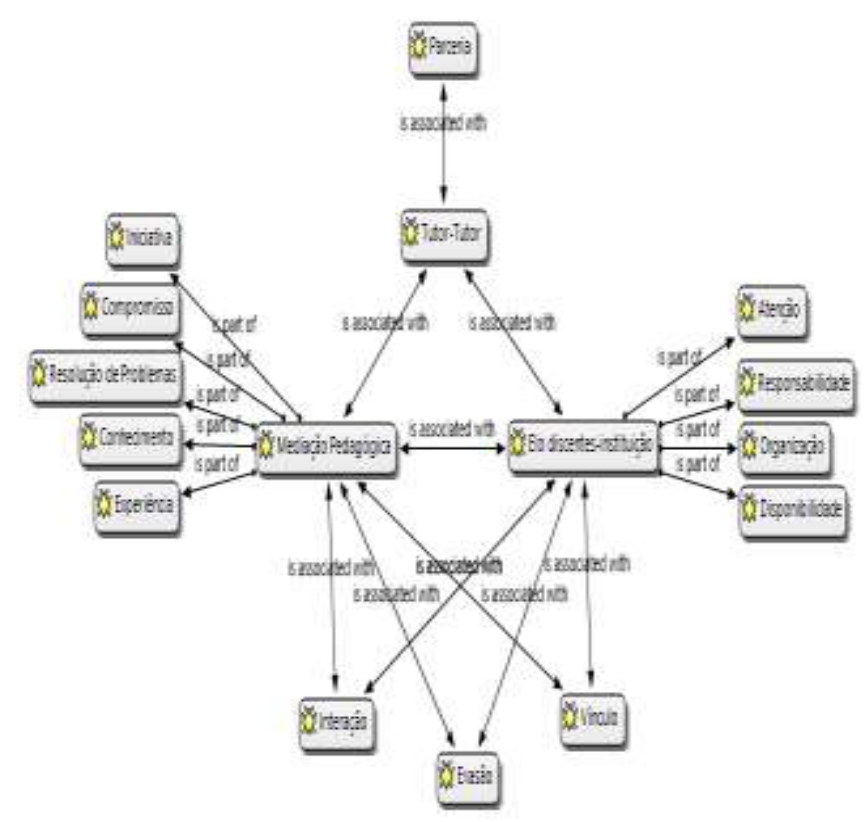

Figura 2 - Mapa de categorias* definidas em função da percepção dos tutores

Fonte: Dados da pesquisa (2016) 
* O Mapa de categorias foi desenvolvido com auxílio do software Atlas ti

Ao lado da mediação pedagógica (eixo 2) há cinco categorias "iniciativa", "compromisso", "resolução de problemas", "conhecimento" e "experiência". Embora esses elementos possam ser conferidos aos dois eixos, as entrevistas indicam que há maior ênfase dessas categorias nas atividades do tutor a distância. A parceria é o componente do sistema $\mathrm{EaD}$ que ressalta a percepção sobre a relevância do trabalho em conjunto em parceria para o bom desempenho do sistema (RONCHI; ENSSLIN; ENSSLIN, 2012), com funcionamento em rede (BERNARDI; DAUDT; BEHAR 2013).

Atribui-se ao tutor a distância a necessidade de iniciativa e experiência, em decorrência, inclusive, desse tutor pertencer a um sistema de $\mathrm{EaD}$ recente. O compromisso, por sua vez, é reforçado como um comportamento relacionado à boa qualidade do curso por favorecer a participação dos tutores nas questões cotidianas do sistema e, também, qualificar a interação com discentes e equipe $\mathrm{EaD}$.

O conhecimento agrega à função de tutoria no sentido possibilitar maior domínio na mediação pedagógica, com amparo da atribuição de auxiliar o desenvolvimento de tarefas propostas pelo docentes das disciplinas (MENEGUETTI, 2004). Por fim, a iniciativa, o conhecimento, a experiência e o compromisso com o curso habilitam o tutor a atividade de resolução de problemas (BELLONI, 2003), ensejando criticidade (PRETI, 2003) e práxis(FREIRE, 2006).

Vinculado ao Elo discente-instituição (eixo 3) têm-se as categorias "atenção", "responsabilidade", "organização" e "disponibilidade". Da mesma forma expressa no eixo 2, esses elementos possam ser conferidos aos dois eixos, as entrevistas indicam que há maior ênfase dessas categorias nas atividades do tutor presencial.

A expectativa em torno do tutor presencial manifesta nos dados indicam maior disponibilidade para o atendimento de demandas, devendo estar sempre "prontamente" a prestar seus serviços. Nesse sentido, esse ator é avaliado pela sua agilidade em relação à atenção, responsabilidade e organização para com essas demandas, em geral, dos docentes e tutores a distância. Surgem elementos que o associam à organização dos encontros presenciais, com atribuições técnico-operacionais, e, pela importância de viabilizar esses encontros, há ênfase na responsabilidade de exercer papel de mediar o contato físico entre discentes e representantes do sistema $\mathrm{EaD}$, no caso, docentes e tutores a distância.

As categorias "interação", "vínculo" e "evasão", surgem como representes dos dois eixos, a medida que congregam manifestações relacionados aos dois públicos de tutores em 
proporção semelhante, denotando o teor mais abrangente dessas categorias. No que diz respeito à interação, pelo ambiente virtual, no caso dos tutores a distância, ou com amparo em contato físico via polo de apoio presencial, ou por e-mail e uso da telefonia, esses atores enfatizam o aspecto interacional como requisito importante para o desempenho das funções tutorias e, consequentemente, melhoria da formação discente.

Em relação ao vínculo, há manifestações que reforçam sua relevância como categoria de maior importância para que se estimule a permanência discente (BIZARRIA et al., 2015). O vínculo, sendo fruto de um processo interacional, é expresso como os laços constituídos pelos atores do sistema $\mathrm{EaD}$, em especial os tutores, que caminham para fortalecer o sentimento de pertencimento ao curso, ao grupo e a instituição (HOLMBERG, 1996).

\subsection{Avaliação de Tutores: o olhar dos alunos}

A figura 3 indica a categorização, com referência nos eixos 1,2 e 3 , tendo como dados a percepção dos discentes sobre avaliação da tutoria no sistema $\mathrm{EaD}$.

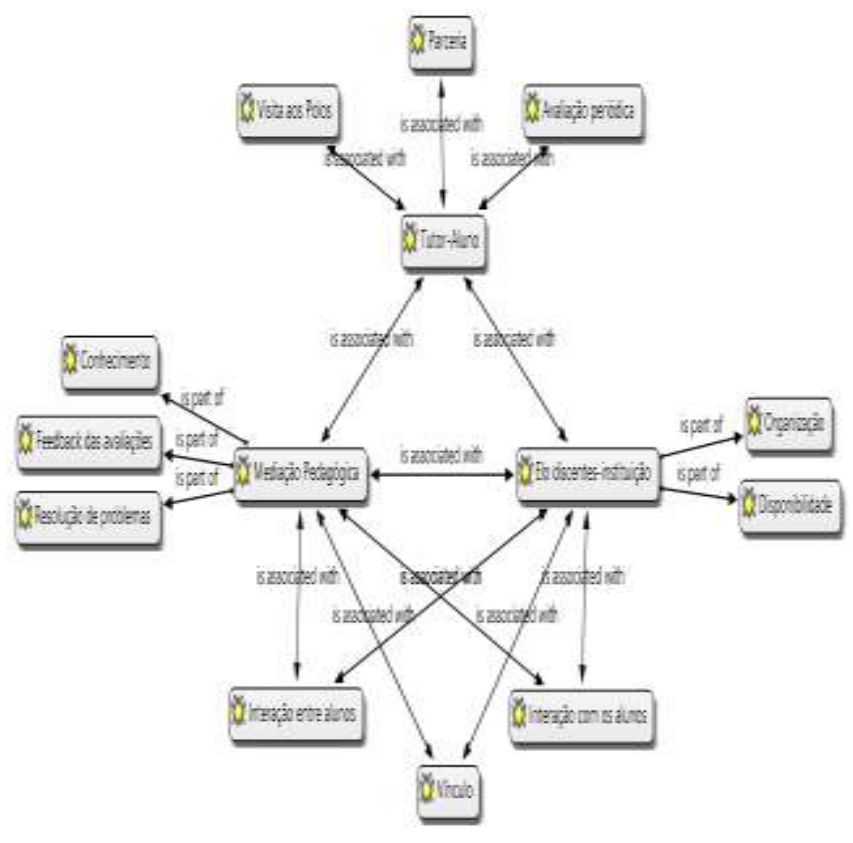

Figura 3 - Mapa de categorias* definidas em função da percepção dos alunos

Fonte: Dados da pesquisa (2016)

* O Mapa de categorias foi desenvolvido com auxílio do software Atlas ti

A percepção discente indica nova organização categórica. Associados à Mediação Pedagógica (eixo 2), encontram-se elementos agrupados em torno do "conhecimento", da "resolução de problemas" e do "feedback das avaliações". Para os discentes, domínio do conteúdo por parte dos tutor a distância expressa maiores possibilidade de sucesso, haja vista que qualifica os auxílios e melhor prepara os discentes para as atividades do curso (BELONI, 2003; WROBEL et al., 2010; MEDEIROS; MOSER; SANTOS, 2015). Dessa forma, associa-se o processo de tutoria ao bom desempenho discentes, ressaltando que o conhecimento também habilita tutores na tarefa de resolução de problemas, em geral, 
relacionados aos conteúdos do curso e, também, compreensão das mensagens disparadas pela coordenação e pelos docentes. Nesse caso, há expectativa de "tradução" do que se espera dos discentes em suas atividades e, para isso, o conhecimento dos conteúdos habilita o tutor a melhor interagir diante dessa expectativa.

Há intensas considerações sobre a atribuição "feedback das avaliações", como momento de auto avaliação discente e definições em relação ao percurso de aprendizagem. Assim, além de situarem a importância de se obter feedback com agilidade, são requeridas interações que viabilizem o retorno comentado do feedback, para este possa guiar o processo de aprendizagem futuro, na direção da melhoria da qualidade do processo (VALENTE; MORAN, 2011), bem comoacompanhamento dos cursos(PASSOS; BATTESTIN, 2016).

Além do componente "parceria", outros duas categorias emergem dos dados, a "visita aos polos" e a "avaliação periódica". As três indicam, no âmbito de uma perspectiva de avaliação tutorial, que é necessário agregar o olhar sistêmico, incorporando análises processuais (avaliação periódica), com observação de especificidades de cada realidade (análise por polo) e, assim, melhorar estratégias de Planejamento e de Gestão dos cursos de EAD (RISSI et al., 2012).
Em associação ao Elo-discentesinstituição (eixo 3), indicam-se dois grupos, "organização" e "disponibilidade". Nesse caso, a mesma consideração a respeito do eixo 2 foi identificada, haja vista que a expectativa em torno do tutor presencial esta relacionada aos encontros presenciais, sendo a disponibilidade e organização requisitos necessários ao melhor aproveitamento desses momentos por parte dos demais atores.

A dimensão interacional surge em falas de tutores e discentes, em consideração aos dois eixos do estudo, haja vista que por meio da interação discentes e tutores estreitam o aspecto comunicacional, dialogando com o acolhimento de demandas (BIZARRIA et al., 2015). As categorias "interação entre alunos", "vínculo" e "interação com os alunos", surgem como representes dos dois eixos. A interação suscitada no eixo 2 é desmembrada no eixo 3 , considerando que duas formas de interação são elaboradas em torno dos dados. Há manifestações que entoam a interação dos tutores com os discentes, mas, para além disso, espera-se interação propositiva em torno do fortalecimento dos grupos. Nesse caso, a interação entre grupos surge como necessidade anterior à realização das atividades de grupo, haja vista que o trabalho em grupo só flui quando o grupo possui histórico de interações anteriores, quando os componentes possuem maior sintonia favorável a uma construção conjunta. 
Assim como no eixo 2, há considerações sobre a vinculação desenvolvida nos processos interativos e na sua relevância na construção de referencias para o discentes, em associação aos sentimentos que os fortalecem no processo de ensino-aprendizagem e, como isso, as chances de sucesso nos cursos.

\section{Considerações Finais}

Diante da perspectiva de contribuir com a discussão sobre avaliação na Educação a Distância $(\mathrm{EaD})$, especificamente em relação a atividade de tutoria, objetivou-se elaborar aspectos dessa atividade que pudesse nortear processos avaliativos futuros, considerando dados coletados com 45 tutores a distância, 28 tutores presenciais e 145 discentes, vinculados a 1 curso de graduação (Administração Pública) e 3 cursos de especialização (Gestão Pública, Gestão em Saúde e Gestão Pública Municipal) oferecidos em 5 polos de apoio presencial no Estado do Ceará e 1 polo no Estado da Bahia.

Duas formas de considerar avaliação de tutoria foram analisadas, uma sob o ponto de vista dos tutores e outra sob o ponto de vista dos discentes. No primeiro caso observase maior distinção entre as funções atribuídas aos dois tipos de tutoria, à medida que se vincula à mediação do tutor a distância atribuições correlatas à dimensão pedagógica (conhecimento e experiência) e expectativas comportamentais (iniciativa e compromisso) favoráveis a construção de repertório para a resolução de problemas. Tal distinção é propagada por documentos oficiais (BRASIL, 2007, 2016)e, por isso, é considerada pelos sistemas de ensino EaD. Por sua vez, ao tutor a distância são definidas funções técnicooperacionais (organização), associadas ao perfil profissional necessário para essas funções (responsabilidade e atenção) em associação à disponibilidade, o que ressalta a importância de discutir e discernir funções operacionais das funções pedagógicas (RONCHI; ENSSLIN; ENSSLIN, 2012). As duas tutorias se cruzam na perspectiva de interação, construção de vínculos e suporte à problemática da evasão discente.

Sob o ponto de vista discente a avaliação de tutores situa de forma menos acentuada a distinção dos tutores, inclusive porque seu maior contato é com os tutores a distância. Há considerações mais objetivas em torno das expectativas agrupas em torno de um maior domínio dos conteúdos das disciplinas (conhecimento), expressando, também, maior formação para o auxílio (resolução de problemas) e o retorno das avaliações disciplinares e da própria tutoria, como forma de situar o andamento do processo individual de ensino-aprendizagem, bem como adentrar no conhecimento do sistema de ensino ao qual está vinculado. 
Considera-se, também, que o tutor presencial se situa no sistema em função de sua organização e abertura para o atendimento das demandas.

Observando-se os dois pontos de vista infere-se que os discentes buscam avaliações mais próximas de suas realidades, quando comportamentos desejados sejam expressos em ações avaliadas, seja por meio do cumprimento de prazos, visita aos polos, ou retorno das avaliações. Nesse sentido, observa-se aspectos de distanciamento de compreensão das atividades de tutoria desses atores, quando os tutores manifestam-se em torno de um perfil ideal, ressaltando as qualidades para o exercício da tutoria e, no caso dos discentes há ênfase nos aspectos reais cotidianos, que impactam o processo de ensino-aprendizagem desse grupo.

Em termos genéricos, em função de um conhecimento que se desenvolve em fluxo (TARCIA; CABRAL, 2012), e compreendendo-se que o fluxo da avaliação pressupõe conhecer, compreender, orientar e reorientar processos e ações (BELLONI; MAGALHÃES; SOUSA, 2007),considera-se pertinente pensar em processos avaliativos que agreguem os diferentes pontos de vista, sendo o retorno periódico dessas avaliações um exercício necessário à credibilidade da própria avaliação e, também, favorável a construção do diálogo, sendo a dimensão dialógica intrínseca à educação(FREIRE,
1983), tendo como objetivo alinhar expectativas às ações, ou a construção de expectativas em função de ações reais, possíveis e desenvolvidas em parceria com todos os atores do sistema, incluindo os polos de apoio presencial como protagonistas nesse processo, com o intuito de aprimorá-lo.

Destaca-se também como necessáriorediscutir a distinção entre tutores e de como essa distinção impacta suas atribuições, inclusive no que diz respeito ao aspecto valorativo associado à casa categoria bem como o embate da dualidade entre inciativa (tutor a distância) versus passividade (tutor presencial), que pode repercutir em segregação e alienação do processo. Nesse caso, propõem-se que todos possam ter oportunidade para exposição de ideias e elaborações propositivas para o curso, em função da experiência o do lugar que cada um assume no sistema.

A pesquisa não encerra uma proposição de instrumento de avaliação, e, também, não vislumbra propagar categorias definitivas. A intensão foi levantar grupos de informações situadas na manifestação de tutores e discentes que pudessem auxiliar processos avaliativos futuros, especialmente na instituições onde o estudo foi realizado. Nesse sentido, acredita-se no êxito em torno do que foi proposto e estimula-se que esse levantamento, ou parte dele, possa ser (re)elaborado, refinado e/ou redimensionado 
em pesquisas futuras, agregando outras possibilidades de intervenção metodológica e analítica. Considera-se, também, pertinente que se busque a fala de outros atores do sistema, especialmente docentes, o que apresenta-se como importante limitação desse estudo.

\section{Referências}

ALMEIDA, N. L. de O.; MARROIG, R.; PINTO, V. R. R. Competências e habilidades do tutor virtual que influenciam na aprendizagem dos alunos. Revista Pensamento Contemporâneo em Administração, Rio de Janeiro, v. 8, n.2, abr./jun., p. 144-166, 2014.

ARAUJO, E. M. de et al. A gestão da inovação na educação a distância. Gest. Prod., São Carlos, v. 20, n. 3, p. 639-651, 2013.

BANDEIRA-DE-MELLO, R. Softwares em pesquisa qualitativa. In: GODOI, C. K.; BANDEIRA-DE-MELLO, R.; SILVA, A. B. (Orgs.). Pesquisa Qualitativa em Estudos Organizacionais -Paradigmas, Estratégias e Métodos. São Paulo: Saraiva, 2006.

BARDIN, L. Análise de conteúdo. Lisboa: Edições 70, 2011.

BELLONI, I.; MAGALHÃES, H. de; SOUSA, L. C. Metodologia de Avaliação em Políticas Públicas. 4. ed. São Paulo: Cortez, 2007.

BELLONI, M. L. Educação a distância. 3.ed. Campinas: Autores Associados, 2003.

BELLONI, M. L. Educação a Distância. Campinas: Autores Associados, 1999.
BERNARDI, M.; DAUDT, S. D.; BEHAR, P. A. Domínio da Gestão em Educação a Distância. In: BEHAR, P. A. (Ed.),Competências em Educação a Distância. Porto Alegre: Penso, 2013.

BIZARRIA, Fabiana Pinto de Almeida. Formulações Estratégicas e Processo de Institucionalização no Enfrentamento da Evasão Escolar no Ensino a Distância à Luz da Adaptação Estratégica em Uma Instituição de Ensino Superior do Estado do Ceará.Dissertação (Mestrado em Administração de Empresas) -Universidade de Fortaleza (UNIFOR), 2014.

BIZARRIA, F. P. de A.; SILVA, M. A. da; TASSIGNY, M. M.; CARNEIRO, T. C. J. Papel do tutor no combate à evasão na EAD: percepções de profissionais de uma instituição de ensino superior. Revista Educação, Ciência e Cultura, v. 20, n.1, 2015.

BRASIL, Ministério da Educação, Conselho Nacional de Educação. Diretrizes e Normas Nacionais para a oferta de Programas e Cursos de Educação Superior na Modalidade a Distância. Diário Oficial da União de 10 de março, Seção 1, página 22, 2016.

BRASIL. Ministério da Educação. Secretaria de Educação a Distância. Referenciais de qualidade para educação superior a distância. Brasília, DF: MEC, 2007.

BRUNETTA, N.; LOCATELLI, P. A. P. C.; SAWITZKI, R. C.; ANTUNES, E. D. D. As representações sociais dos tutores sobre a atividade de tutoria em cursos de especialização em Administração na modalidade a distância. Organizações em Contexto, São Bernardo do Campo, v. 9, v. 17, n. 17, jan./jun. 2013.

DEMO, P. O mais importante da educação importante. São Paulo: Atlas, 2012. 
FRANKLIN, T.; VAN HARMELEN, M. Web 2.0 for content for Learning and Teaching in Higher Education. Bristol: JISC. Retrieved November 9, 2007.

FREIRE, P. Extensão ou Comunicação. 7. ed. Rio de Janeiro: Paz e Terra, 1983.

FREIRE, P. Pedagogia da Autonomia: saberes necessários à prática educativa. São Paulo: Paz e Terra, 2006.

FREITAS, M. T. M.; FRANCO, A. P. Os desafios de formar-se professor formador e autor na Educação a Distância. Educ. rev., Curitiba , n. spe4, p. 149-172, 2014.

HATTUM-JANSSEN, N.V.; VASCONCELOS, R. The role of the tutor in project-led education: the developement of an evaluation instrument. In: International

Conference on Engineering and Technology Education. São Paulo, 2008.

HOLANDA, V. R. de.; PINHEIRO, A. K. B.; PAGLIUCA, L. M. F. Aprendizagem na educação online: análise de conceito. Rev. bras. enferm., Brasília, v. 66, n. 3, p. 406411, jun. 2013.

LANZA, B. L. B.; KUABARA, P. S. S. Democratization of Education in Brazil: Distance Education at the Federal University of Paraná.US-China Education Review B, November, v. 5, n. 11, 701-713, 2015.

LUCKESI, C. C. Avaliação da Aprendizagem. São Paulo/SP: Cortez 2011.

MAGGIO, M. O tutor na educação a distância. In: LITWIN, E. (Org.) Educação a Distância: temas para o debate de uma nova agenda educativa. Porto Alegre: Artmed, 2001.

MARTINS, L. B.; ZERBINI, T. Educação a distância em instituições de ensino superior: uma revisão de pesquisas. Revista
Psicologia: Organizações e Trabalho, v. 14, n. 3, jul.-set., pp. 271-282, 2014.

MAYFIELD, M. Creating training and development programs: using the ADDIE method, development and learning in organizations, Vol. 25 Iss: 3 pp. $19-22$. 2011.

MEDEIROS; L. F. de.; MOSER, A.; SANTOS, N. dos. Assistente de conhecimento conceitual como um sistema intencional para processos tutoriais em Educação a Distância. Perspectiva em Gestão \& Conhecimento, João Pessoa, v. 5, n.1, p. 155-168, jan./jun., 2015.

MENDES, V. O trabalho do tutor em uma instituição pública de ensino superior. Belo Horizonte. Educação em Revista, Belo Horizonte, v. 28, n. 2, p. 103-132, 2012.

\section{MENEGHETTI, A.F. Professor} pesquisador/reflexivo: o olhar de tutores da Educação a Distância. Florianópolis, 2004. Dissertação (Mestrado em Educação) Universidade Federal de Santa Catarina.

MINAYO, M.C.S. O desafio do

conhecimento: pesquisa qualitativa em saúde. São Paulo: Hucitec, 2007.

MOORE, M. G.; KEARSLEY, G. Educação a Distância: uma visão integrada. São Paulo: Cengage Learning, 2008.

PASSOS, M. L. S.; NUNES, V. B. Innovative Management in Distance Education-The Importance of Monitoring Meetings in a Postgraduate Course in the Multidisciplinary Team Perspective. US-China Education ReviewA, Jan., vol. 6, No. 1, 63-69. 2016.

RISSI, M. et. al. Conflitos Inter organizacionais em equipes que atuam com a Educação a Distância (EAD). Revista Novas Tecnologias na educação, v. 10 , n. 3, p. 210, dez. 2012. 
RONCHI, S. H.; ENSSLIN, S. R.; ENSSLIN, L. Estruturação de um modelo multicritério para avaliar o desempenho da tutoria de Educação a Distância. PRETEXTO, Belo Horizonte, v. 13, n. 2, p. 57-75, abr./jun., 2012.

SOUZA, J. C.; FARIA, M. F. B. Gestão de sistemas de Educação a Distância na perspectiva da inovação. In: MIL, D.;

MACIEL, C. (Eds.)Educação a Distância: Elementos para pensar o ensino aprendizagem contemporâneo. Cuiabá: EdUFMT, 2013.

SUN, P. C.; TSAI, R. J. FINGER, G.; CHEN, Y. Y.; YEH, D. What drives a successful eLearning? An empirical investigation of the critical factors influencing learner satisfaction. Computers \& Education, v. 50, n. 4, p. 1183-1202, 2008.

TARCIA, R. M. L.; CABRAL, A. L. T. O novo papel do professor na EaD. In: LITO; F. M.; FORMIGA, M (orgs.) Educação a

Distância: o estado da arte. 2. ed. São Paulo: Pearson Education do Brasil, 2012.

VALENTE, J. A.; MORAN, J. M. Educação a Distância: pontos e contrapontos. São Paulo: Summus, 2011.

WROBEL, J. S.; CARNEIRO, T. C. J.; PALMA, W. de S.; AGUIAR, L. B. Tutoria em Educação a Distância: teoria, prática, aprendizados e desafios. Administração: Ensino e Pesquisa, Rio de Janeiro, v. 11, n. 3, p. 331-354, jul./ago./set., 2010.

ZERBINI, T.; ABBAD, G. Reação ao Desempenho do Tutor em um Curso a Distância: Validação de uma Escala. Estudos e Pesquisas em Psicologia, Rio de Janeiro, v. 9, n. 2, p. 447-463, 2009.

ZERBINI, T.; BORGES-FERREIRA, M. F.; ABBAD, G. da S. Medidas de reação a cursos a distância. In: ABBAD, G. da S. et al.

Medidas de Avaliação em Treinamento,
Desenvolvimento e Educação. Porto Alegre: Artmed, 2012. 